\title{
A Comparative Study of Shift Work: Days, Nights, and Weekends: Which Shift Yields Higher Output and Lower Defects
}

\author{
Keeley McConkey ${ }^{1,2}$ \& Ekaterina Koromyslova ${ }^{1}$ \\ ${ }^{1}$ Department of Construction and Operations Management, South Dakota State University, Brookings, SD, USA \\ ${ }^{2}$ Electronic Assembly Department, Daktronics, Brookings, SD, USA \\ Correspondence: Keeley McConkey, Department of Construction and Operations Management, South Dakota State \\ University, Brookings, SD, USA.
}

Received: June 12, 2018

Accepted: June 27, 2018

Online Published: July 1, 2018

doi:10.5430/jms.v9n3p18

URL: https://doi.org/10.5430/jms.v9n3p18

\begin{abstract}
The purpose of this study is to determine if there are statistically significant differences in the performance output for three different shifts in an electronic manufacturer. The primary focus of this paper will study day, night, and weekend shift and compare productivity using Analysis of Variance. The secondary focus of this paper is to understand if variables such as shift, number of changeovers, and management affect productivity and quality using Multiple Regression. By understanding if and what these differences are, manufacturing can be optimized to provide consistency across the different shifts.

Statistical analysis indicated that there are differences in productivity among two value streams, while the remaining two indicated no differences. Furthermore, one value stream revealed that changeovers affect productivity while shift and management were insignificant factors for all value streams.
\end{abstract}

Keywords: productivity, quality, shift work, management, changeover, value-stream, anova, multiple regressions

\section{Introduction}

Manufacturing in the United States is driven by competition and market demand. In order to meet the demand, most manufacturing industries have two to three production shifts: days and nights, days, nights, and weekends, or a rotating shift. This research paper discusses the performance of the production shifts at Daktronics Inc., located in Brookings, South Dakota. Daktronics is leading the industry internationally in designing and manufacturing electronic scoreboards, programmable display systems, and large screen video displays. The Electronic Assembly (EA) department supports all products. EA is broken down into four main value streams and technologies shown in Figure 1. Master location 140 (ML140) produces high volume, low mix display systems, while master location 160 (ML160) produces low volume, high mix control systems. On these value streams, there is a range of through-hole, surface mount, and mixed technology electronics.

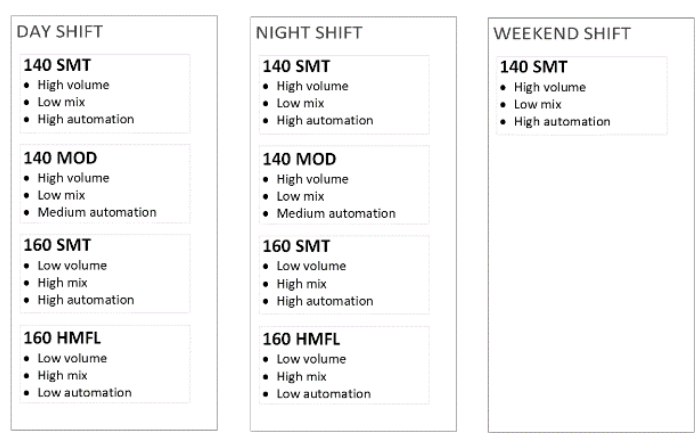

Figure 1. Electronic assembly value stream and shift breakdown

Description: Breakdown of value stream for each shift in the electronic assembly department. Day shift and night shift have all value streams while weekend shift only produces on ML140 SMT. 
While all value streams produce different products using different technologies, they are all structured similarly in respect to their staffing. All value streams utilize the day shift. This shift is the primary shift and has the most support. Organizational chart, shown in Figure 2 demonstrates that.

With the plant manager, engineering manager, maintenance supervisor, and programmers, the day shift is the highest supported shift in the Electronics Assembly Department at Daktronics. Next are the night shift and weekend shifts. Both shifts are structured the same, with less support from the plant manager, engineering manager, maintenance supervisor, and programmers. The night and weekend shifts have production supervisors who manage crew leaders and production operators. These shifts also have maintenance and process technicians to support and maintain equipment.

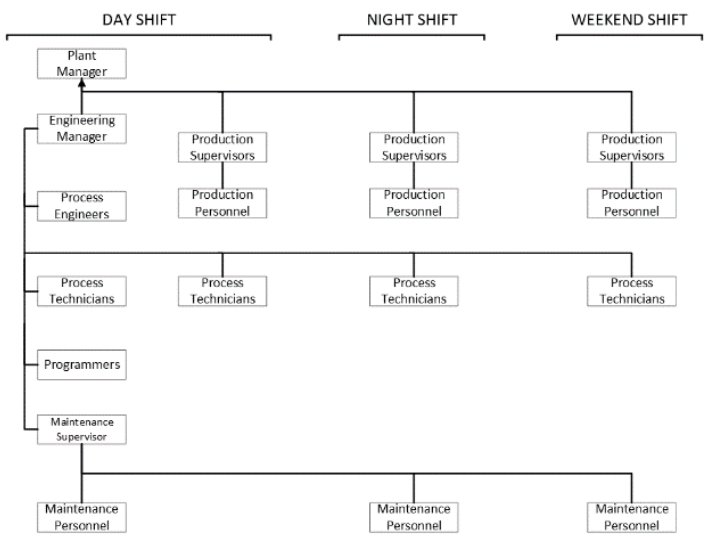

Figure 2. Electronic assembly organization chart

Description: Organization chart of Electronic Assembly shows how each shift is staffed. In addition to what night and weekend shift have, day shift has a plant manager, engineering manager, value stream engineers, programmers, and a maintenance supervisor.

The best interest of the company, regardless of the industry they are in, is to produce equally and efficiently across all two or three shifts. However, there is little information or research to evaluate if a certain shift surpasses the other shifts in regards to production output, quality, and safety incidents.

\subsection{Statement of Need}

The need for this study comes from management within Daktronics. There was a case when the ML140 MOD line had significantly more production output on the second shift than the first shift the day before. Both shifts were running the same product, on the same equipment with the same capacity, and with the same amount of operators. They should have had similar outputs between the shifts, but one outperformed the other with no explanation. There was no significant downtime on the first shift that hindered production; the only explanation was that second shift produced more. The results should be useful and valuable to other manufacturing companies seeing similar output inconsistencies. This study will help Daktronics explain if there is a dissimilarity between all of their shifts and what can be done in order to make these shifts parallel. Therefore, process improvement can be better utilized, quality can be more controlled, and production costs can be reduced.

With standards and automation in place, production goals should be the same across all shifts, but this may not always be the case. Likewise, quality and safety incidents should see similarities across all shifts. All shifts are using the same equipment with the same cycle time, tolerances, and machine guarding. What is not necessarily clear is if production bypasses certain standards to increase their output or remove guarding to produce more. This may be the situation in the Electronic Assembly department. On occasion, production from one shift significantly exceeds goals, or has considerably higher defects than the other shifts. While it may be obvious to see major differences, over time slight differences are not always noticeable. This study will address those differences and evaluate if there is a variation between the various shifts or if those goal bypasses are just anomalies.

\subsection{Problem of the Study}

The problem of this study is to determine if there are statistically significant differences in the performance output 
for three different shifts in the Electronic Assembly Department of Daktronics on the corporate campus in Brookings, South Dakota.

The purpose of this study is to provide recommendations to the Daktronics management on how to reduce the dissimilarities, if any, between all of their shifts.

This study is twofold. We want to determine both if there is a difference in output between shifts and if specific factors, such as 'shift', 'supervisor support', and 'number of changeovers', affect the output of each shift. Thus, we need to answer the following research questions:

1) Is there a noteworthy difference in productivity between the different manufacturing shifts?

2) Does the support of engineering and management hinder the performance of day shift, preventing production from bypassing goals or does reduced support allow night and weekend shifts to bypass standards set by engineering to allow higher production goals?

3) Is there correlation between productivity and quality in each shift?

\subsection{Research Hypotheses}

It is hypothesized that there are inconsistencies in outputs between the shifts of the same value stream. For this study, the hypothesis is that productivity of first shift, second shift, and weekend shift all differ from each other.

$\mathrm{H}_{0}$ : All shifts (day, night, and weekend) have the same productivity

$\mathrm{H}_{1}$ : There is a difference in productivity in at least one shift for each value stream

This hypothesis will be tested for ML140 SMT, ML140 MOD, ML160 SMT, and ML160 HMFL

It is hypothesized that such factors as shift, supervisor support, and number of changeovers affect productivity:

$\mathrm{H}_{0}$ : Factors such as shift, supervisor support, and number of changeovers, do not affect productivity

$\mathrm{H}_{1}$ : Different factors do affect productivity

This hypothesis will be tested for ML140 SMT, ML140 MOD, ML160 SMT, and ML160 HMFL with the exception of changeovers which will be limited to ML160 SMT and ML160 HMFL.

Initially there was an intention to analyze safety incidents as a factor, but after data collection it became clear that safety incidents did not occur often enough to impact productivity.

\subsection{Assumptions}

The following assumptions are made for the purpose of this study:

1) This study was conducted during live production. No intentional interference was done to collect data.

2) Machine downtime was uncontrolled and unplanned. It was assumed that over the course of the study, machines have gone down, causing lost production across all shifts.

3) When production downtime was caused by hindered machines, operators from the affected line were distributed to other value streams.

4) The ML140 SMT and MOD line produce high volume, high consistency products.

5) The ML160 SMT and HMFL line produce low volume, low consistency products.

6) Day shift and night shift work on a four-10 hour schedule.

7) Weekend shift work on a three-12 hour schedule.

\section{Literature Review}

\subsection{Introduction}

The purpose of the literature review is to study the topic of shift work and determine what research has been conducted that will aid in directing this study. Using past research to study productivity and health and safety, as well as their impact to productivity, help lay a foundation to this research. Many studies exist explaining how night shift typically has higher health incidents and lower health and awareness overall (Ogiński, Ogińska, \& Pokorski, 2000; Costa, 2010; Kalmbach, Pillai, Cheng, Arnedt, \& Drake, 2015; Lee et al., 2016; Travis et al., 2016). There is a gap in literature regarding any other factors, besides health and safety, which contribute to difference in productivity in different shifts.

As productivity is the basis of this study, it is also important to include how shiftwork has evolved over the years. 
Nearly 100 years ago, a typical work week looked different than it does now due to lack of regulations. To favor a worker, government regulations have been created to minimize fatigue and risk to the worker. The next section will provide some history and background shiftwork.

\subsection{Background to Shift Work}

A 40-hour work week has been the standard in labor hours for nearly 80 years since 1938 when the Fair Labor Standards Act (FLSA) was passed. Prior to this law, there were no ceilings for how many hours an employee could work, how much an employee could be paid, or even how young an employee had to be in order to work (Grossman, 1978). Prior to this, it was common for someone to work 44 or 48 hours a week. To comply with that law, multiple companies lost productivity as now the $48+$ hour work week was cut down to 40 hours, setting the new industry standard. With the restrictions from the FLSA, different styles of employment were needed to keep up with demand. This may be one of the reasons that a secondary and tertiary shift exist. As this was one reason for multiple shifts, other reasons to add a second and third shift could be continuous process to maintain production efficiency; lower utilities cost at night; seasonal work to keep up with seasonal demand; supplement day hours to satisfy high demand; and necessity as some companies or job types are required to run 24-hours (King \& Williams, 1985).

In 1914, Henry Ford, innovator of the modern assembly line, developed the standard 40-hour shift, that we are familiar with today, because he felt that productivity was better at 40 hours. Working too much will cause fatigue that can result in loss of productivity as well as in the job safety incidents. The number of hours a person can work is now standardized, but how that shift is structured is not. Typically, employers start with a day shift and add from there. If needed, a second shift, third shift, and/or weekend shift is added. Some companies have become creative and have designed different types of shift structures. Rotating shifts, Oscillating shifts, Split shifts, and Swing shifts exist (King \& Williams, 1985). The FLSA established regulations on the number of hours a person can work as well as the minimum wage a person can be paid, but does not set a standard for type of shift pay incentives for shift work. On average, nine-tenths of late-shift workers are compensated higher or have more incentives than day-shift workers. In 1985, the pay difference was 23.2 cents per hour on second shift and 29.9 cents per hour on third shift (King \& Williams, 1985). Today, that pay difference has increased to $7.5 \%$ on second shift (3pm to midnight) and 10\% on third shift (11pm to 8am) (U.S. Office of Personnel Management, 2017). Assuming average US minimum wage is $\$ 7.25,7.5 \%-10 \%$ is a pay difference of 54.3 cents per hour on second shift and 72.5 cents per hour on second shift (National Conference of State Legislature, 2017). The pay incentive is likely because night shift work is more stressful, more dangerous, and typically not preferred.

As time goes on, one can see the evolution of shift work. Federal regulations have limited the number of hours an employee can work in a week. Changes from this have led to the addition of a second and third shift. If 40 hours is to be split up during a week, it has made sense to work five 8-hour shifts, and have two days off for a weekend. This seems to work, but it may not be the most efficient for an employer. With an 8-hour work day, there are some wastefulness such as: inefficiency and downtime due to shift-change, lack of flexibility in schedule, poor management practices/lack of night or weekend shift management, turnover/low morale among employees, high paid time off/out of office among employees, and increased cost to employees (Frehse, 2012). On an 8-hour shift, overtime can only happen once, and that is at the end of the shift where the employee has to stay late to finish their tasks. This is difficult to schedule, plan, and does not account for a second shift starting subsequent to the first one. It is also difficult to get an 8-hour employee to come in on a sixth day during the week (Frehse, 2012). Inefficiencies in production are another reason three 8-hour shifts are being replaced by two 12-hour shifts. In a 12-hour shift, there is one less shift change than in an 8-hour shift. In general, shift changes result in slightly slower production, breaks in production, and potential for downtime (Frehse, 2012).

Thus, 10-hour and 12-hour shifts have been adopted and utilized throughout industries across the United States. A 10-hour shift consists of four days a week, leaving one day open for an added eight to ten hour overtime shift. The 10-hour shift has been adopted at Daktronics and is currently how production employees work throughout the week. The 12-hour shift has also been adopted at Daktronics for weekend employees. Monday through Thursday, with the addition of a Friday overtime shift is classified as the weekday shift for days and nights at Daktronics. Friday through Sunday is dedicated to the one weekend shift at Daktronics.

\subsection{Productivity}

Productivity is defined as "the effectiveness of productive effort, especially in industry, as measured in terms of the rate of output per unit of input" (Productivity, n.d.). It is apparent that all businesses and organizations strive to optimize productivity by increasing outputs and decreasing inputs. This is the case for this study. The problem to be addressed is whether one shift is more productive than a different shift or if they are fairly consistent with one 
another. One can argue that quality is a form of productivity as defects and rework decrease the productivity in manufacturing. Productivity is a theme that most companies are looking to improve on. Research exists that study productivity in different industries (Pencavel, 2014; Ledebur \& Moomaw, 1983; Al-Refaie, Najdawi, \& Sy, 2015; Sanne, 2016). The difference and requirements for this study is that there is little research on comparing the productivities of one shift over another.

"The Productivity of Working Hours" is a study conducted by John Pencavel of Stanford University (2014). The purpose of this study was to evaluate production and determine if there is a relationship in the number of working hours versus output of goods produced. The author gathered data that observed men, women, and youth workers during World War I in European countries. At this time, it was not uncommon for men to work 70 to 90 hours a week peaking up to 100 hours. The results of this study proved that the relation between hours and output is not linear and decreases after the certain number of hours per week (Pencavel, 2014).

This information has its importance, but is difficult to translate it to manufacturing in today's society. Since the early 1900's, many regulations have been put into practice that protect the employee from working in unsafe environments and working too many hours. The sample that will be studied in this research works 40 hours a week with the exception to overtime or reduced hours based on personal time off. Therefore, it is assumed that output will be unaffected by that variable of working hours.

Some of these studies on productivity use a variety of methods to review and analyze the data. One uses descriptive statistics to provide a summary of the sample (Pencavel 2014). Using this type of analysis, one can record data and provide detailed, quantitative summary of the data and the relationship between variables. Central tendency such as mean, median, mode can be used to compare how far from the center the data deviates. Dispersion is another form of descriptive statistics and can be used to conclude standard deviation or range of the data. Another method used to study productivity is the shift-share analysis. This method examines changes in economic variables. One particular study uses shift-share analysis to compare labor productivity and growth in different regions in the United States (Ledebur \& Moomaw, 1983). This particular method has its benefits but comparing different regions is out of scope for this study. A third research method is data envelopment analysis (DEA), which is used to estimate the efficiency of decision making units (Al-Refaie, Najdawi, \& Sy, 2015). Using DEA, machine efficiency can be calculated. While important, this study is limited to production workers and not the machines used. Similarly, in this study, all shifts will be using the same equipment so the machine variables can be reduced and disregarded. It is assumed that machine variables will be consistent across all shifts and likely considered insignificant to the output and quality per shift. Case study is another method used to analyze productivity. Within a case study, techniques such as observations, work sampling, time studies, historical data, and estimation were used (Sanne, 2016).

From these examples of past research, the methods that best fit this study are the techniques of descriptive and inferential statistics. Analysis of variance (ANOVA) provides beneficial information to compare the many variables in this study. Using ANOVA provides an output worthy of determining difference and the significance of the difference.

\subsection{Health and Safety, Incidents, Fatigue}

Although the intent of this study is not to answer the question if the night shift is the most dangerous one, it can be related to the rest of the study. One can speculate that a shift that causes more fatigue, injuries, or incidents, must produce lower output than other shifts. If they reduce output, they could also lower the quality which can be a form of output. It is easy to assume that fatigue directly affects productivity and that a shift that causes more fatigue will yield lower output. The study was conducted to observe different factors that influence injury in continuous shift work. Past safety and injury records were analyzed from a steel plant based in Cracow, Poland. Results concluded that injury rates were similar across all shifts although more severe injuries occurred during night shift, more injuries occurred during the second part of any shift, more injuries occurred in the summer over winter, and weekend shifts saw the fewest injuries (Ogiński, Ogińska, \& Pokorski, 2000). Since the results of that study showed no major difference, it can be assumed that injuries that happen among the workers in this study will not significantly affect productivity and quality.

It is expected that injury caused on the different shifts will have little effect on the overall production output and quality of the product to be studied. However, fatigue may have more impact on production than a work related injury would. Fatigue is defined as "weariness from bodily or mental exertion" (Fatigue, n.d.). Because of the circadian rhythm, a human body has a natural tendency to be active during times of daylight and to be asleep during nighttime (National Sleep Foundation, 2017). The lack of sunlight at night shifts triggers people's minds to become less alert, resulting in fatigue in production workers. There may not be a direct relationship, but this could be a factor 
in differences between output and quality. There are some other factors that contribute to fatigue such as work related (timing and duration of breaks, work duties, intensity of work), individual related (lifestyle, age, diet, medical records), and environmental related factors (Bowler \& Gibson, 2015).

In this study, work related factors will not change. Work intensity and demand are assumed to remain constant between day shift, night shift, and weekend shift. For this reason, work load will not affect results in this study. Individual related factors will change and could have an impact on the results of this study. Although this will not be covered, and all operators will be generalized, it is possible that certain life styles or stereotypes flock towards night and weekend shift. As stated earlier in the background to shift work section, pay incentives for night shift and weekend shift may attract different personalities or characteristics in workers than pay for day shift work. Lastly, environmental related factors, such as adequacy of sleep, may have an impact to this study but the impact will be unknown. All of these examples of causes of fatigue may or may not have a significant impact on whether one shift outperforms another shift. Further study will need to be conducted to determine if output and quality relating to fatigue are direct results from these factors.

When someone's circadian rhythm is changed and interfered with, shift work disorder (SWD) such as depression and anxiety may develop. SWD affects one's sleep which can have a direct impact on one's work performance (Shift work, 2017). In a study of SWD, it was reported that workers (rotating or nights) indicated poorer mental health and lower quality of life (Kalmbach, Pillai, Cheng, Arnedt, \& Drake, 2015). SWD will not be considered in this study. Daktronics does not have a rotating shift, so it would be assumed that only night shift would be affected by this type of disorder. If output and quality are significantly lower on night shift, this may be an important factor.

One factor that will not be assessed in this study is overtime and it's relation to work related injuries and fatigue. Overtime is likely to happen, but the majority of the production will be conducted during normal 40 hours per week operation. Nevertheless, one study reported that overtime is associated with poorer perceived general health and increased injuries, illnesses, and mortality rates (U.S. Department of Health, 2004). In the same study, extended work shift was defined as 10 to 12-hour shifts as compared with 8-hour shifts. As indicated earlier, 10 to 12-hour or "extended shifts" are becoming more popular for the flexibility and productivity gains. This study will observe two 10-hour shifts and one 12-hour shift so the following information can be directly translated. According to a study by members of the U.S. Department of Health and Human Services (HSS), Centers for Disease Control and Prevention (CDC), and National Institute for Occupational Safety and Health (NIOSH), extended work shifts resulted in deteriorated performance and injuries during long hours (2004). It was also noted that extended work shifts were associated with decreased alertness and increased fatigue, lower cognitive function, decline in attention, as well as increased injuries (U.S. Department of Health, 2004). Further information from this study showed that shifts working 12 hours reported increased health complaints, deterioration in performance, and even slow pace of work (U.S. Department of Health, 2004). This is fairly significant and may have a direct relationship to this study. Since all shifts observed in this study are technically classified as an extended shift, health issues, deterioration in performance, etc. should not be affected from one shift compared to the rest. However, one shift is different than the others being that it is slightly more extended at 12 hours. Based on results from the HSS, CDC, and NIOSH, it can be hypothesized that productivity output will be lower and defects will be higher among the 12-hour weekend shift. Although, health, alertness, fatigue, etc. will not be evaluated in this study, past research might be able to predict certain performance. This study will only observe extended work but will not observe productivity and quality from a standard 8-hour shift. Further research may need to be conducted to determine if 8-hour shifts are more productive than 10 to 12 -hour shifts.

While there might not be a direct link between working different shifts, and working an extended shift versus a standard 8-hour shift, it can be concluded that health is affected from the unnatural work environments that some are subjected to. Whether it is a disturbance in one's circadian rhythm, issues caused by Shift Work Disorder, or working overtime or extended hours, one can agree that mental and physical aspects are affected in humans. These factors may play a key role in increased or decreased production output as well as good and poor quality product. Health factors will not be observed in this study, but past research can help explain some variation in shift work if applicable. Ideally, production output and production quality will stand unchanged from one shift to another but if differences do exist, health aspects in relation to performance may be the answer to "why is there a difference?"

\subsection{Summary}

To conclude, there are a few topics that needed to be addressed to explain where this study is going. Background to shift work and the history of why maximum hours are mandated, why specific pay is defined, and why age of workers builds a foundation to this study. Furthermore, productivity is defined and shown why companies and 
organizations are looking to increase this element. Organizations are constantly looking for ways to increase productivity in order to meet demand. Lastly, health and safety is looked at regarding how it relates to shift work. It is important to keep a worker's fatigue to a minimum in order to gain the most productivity from manufacturing. From this information, especially drawn from the productivity section, methodology for this study will need to be defined.

The next section explains the methods used to collect and analyze data. In this section, the methods for this study will be explained: what data is to be collected and how the study will carry out data collection. Likewise, the methodology section will explain the population of the study and explain how the data will be analyzed using a combination of descriptive and inferential statistics such as analysis of variance, multiple linear regression, simple linear regression, and correlation.

\section{Method}

\subsection{Description of Data}

The data that were collected for this study are broken down into three categories: Days, Nights, and Weekends. Within each of those groups, data were collected for production output, quality, and labor hours. Production output is the number of product produced through a certain process and collected daily. Quality was also collected daily and is described as the total number of defects per day. Lastly, labor hours were collected daily and refer to the number of operators per shift, per manufacturing line, times the number of hours per shift. Using production output and labor hours as the input, productivity is calculated as: Productivity $=$ (production output / labor hours input). These data were collected across all manufacturing lines in the Brookings EA factory.

\subsection{Target Population}

The target population for this study is the Electronic Assembly Department of Daktronics. The Brookings Electronic Assembly Department one year sample data were collected for this study. After the research is complete, further analysis can be conducted for the Sioux Falls and Redwood Falls factories.

\subsection{Data Gathering Plan}

Data were gathered every work day for the one-year period. One shift may have been shut down for a few days. Also, day/night shifts worked four days a week and weekend shift worked three days a week, so a full year would be about 156 to 208 work days. At the end of each day, production output, quality data, and operator hours were finalized and recorded. Data were collected daily for an entire year to account for changes in seasons starting in May 2016. This information was broken down into fiscal quarters and can also be used to determine if there are differences in shifts throughout the year.

Each output that was collected was recorded daily by different groups within Daktronics. For each manufacturing line, the production supervisors and production schedulers recorded production output and stored it within a document for their record. The production supervisors or team leads also logged employee hours and recorded this information in a separate document. The quality data were accumulated and sorted by the quality department. This group used Glovia to log any defects from production and compiled the data into a separate document.

\subsection{Data Analysis and Hypotheses Testing}

For this study, following statistical methods were used to answer the research questions. First, descriptive statistics were used to test the collected data for normality and to evaluate the appropriateness of parametric tests for further analysis. Analysis of variance (ANOVA) was used to test hypotheses and to calculate if there is statistically significant difference in means between the shifts. Multiple linear regressions were used to determine which factors affected productivity. The reason for using these statistical analysis methods are due to the fact that there are multiple independent and dependent variables. Simple linear regression and correlation analyses were conducted to investigate relationship of quality and productivity, as well as influence on quality of the following factors: shift, management, and number of changeovers. Microsoft Excel was used to store data from data collection, to analyze the data, and to evaluate the results. The output of the MS Excel data was used to draw conclusions from the study. Null hypotheses were either rejected or we failed to reject them based on obtained $p$-values compared with $\alpha=0.05$ for the chosen confidence interval of $95 \%$. In this study, multiple value streams were analyzed and it was expected that results may vary between high mix and low mix. This is addressed in the conclusion of this study.

The next section will report the data analysis in detail. Procedure and output for the normality test are presented in the next section, as well as results from the ANOVA and regression tests. All hypotheses stated in section 1 were tested, and the results for each value stream are provided in the next section. Results from the simple linear 
regression test are also discussed in relation to each variable as it pertains to the independent variable quality as well as determining if productivity and quality are correlated.

\section{Results}

Prior to analyzing the data, it was necessary to test for normality to ensure that ANOVA and Multiple Regression would provide a proper fit to the data. For all four value streams, the data did in fact represent normality so proper analysis could begin.

\subsection{Analysis of Variance}

Analysis of variance will be used to test the hypothesis to determine if there are any differences in productivity from day shift, night shift, and weekend shift. The hypothesis for this is:

$\mathrm{H}_{0}$ : All shifts (day, night, and weekend) have the same productivity

$\mathrm{H}_{1}$ : There is a difference in productivity in at least one shift

This hypothesis is tested for all four value streams.

Table 1. Analysis of variance summary table

\begin{tabular}{llcc}
\hline Source of Variation & F & df & P-value \\
\hline ML160 HMFL* & & & \\
Day/Night & 11.3968636 & 254 & 0.000851399 \\
ML160 SMT** & & 258 & 0.396666414 \\
Day/Night & 0.720816272 & & \\
ML140 SMT** & & 489 & 0.375945596 \\
$\begin{array}{l}\text { Day/Night/Weekend } \\
\text { ML140 MOD* }\end{array}$ & 0.980278755 & & \\
Day/Night & 6.394325636 & 273 & 0.012014436 \\
\hline
\end{tabular}

*P-value $<0.05 \alpha$ reject null hypothesis

**P-value $>0.05 \alpha$ fail to reject null hypothesis

Description: ANOVA summary table includes each value stream and the results of the ANOVA analysis. Included are the $\mathrm{F}$ values, degrees of freedom, and $\mathrm{P}$ values.

Using ANOVA to analyze differences in productivity, it can be concluded that both SMT value streams (ML140 and 160) fail to reject the null hypothesis meaning there is no difference in productivity across the different shifts. However, ML160 HMFL and ML140 MOD reject the null hypothesis meaning there is a difference in productivity between day shift and night shift.

\subsection{Multiple Linear Regressions}

Besides difference in productivity, we need to determine which factors are significant to affecting productivity. Once these are noted, Daktronics can focus on ways to reduce differences. Investigation of all possible factors is out of scope for this study because we cannot control all variables for the analysis purpose. But this is important for Daktronics management team to understand if the three specific factors, shift, supervisor support, and number of changeovers, affect productivity and quality. For this purpose we test the following hypothesis using multiple linear regressions in this study.

$\mathrm{H}_{0}$ : Factors such as shift, supervisor support, and number of changeovers, do not affect productivity

$\mathrm{H}_{1}$ : Different factors do affect productivity 
Table 2. Multiple regressions summary table

\begin{tabular}{lllll}
\hline Source & Coefficient & $\begin{array}{l}\text { Standard } \\
\text { Error }\end{array}$ & t Stat & P-value \\
\hline ML160 HMFL** & & & & \\
Changeover & 0.0483 & 0.0278 & 1.7328 & 0.084359094 \\
Shift & 0.3354 & 0.3754 & 0.8934 & 0.372472973 \\
Management & -0.2905 & 0.2652 & -1.0952 & 0.274436128 \\
ML160 SMT* & & & & \\
Changeover & -0.4301 & 0.0678 & -6.3404 & $1.0348 \mathrm{E}-09$ \\
Shift & -1.1834 & 0.6978 & -1.6957 & 0.091145239 \\
Management & 0.01100 & 0.4261 & 0.0258 & 0.979411676 \\
ML140 SMT** & & & & \\
Shift & 0.2135 & 0.3826 & 0.5579 & 0.577111651 \\
Management & -0.1950 & 0.4693 & -0.4155 & 0.677911863 \\
ML140 MOD** & & & & \\
Shift & 0.01305 & 0.2228 & 0.0585 & 0.953341375 \\
Management & -0.23019 & 0.1571 & -1.4646 & 0.144162646 \\
\hline
\end{tabular}

*P-value $<0.05 \alpha$ reject null hypothesis

**P-value $>0.05 \alpha$ fail to reject null hypothesis

Description: Multiple regressions summary table includes each value stream and the results of the multiple regression analysis. Included are the coefficients, errors, test statistics, and P values.

Using Multiple Regression to analyze factors that affect productivity, it can be concluded that none of the factors tested affect productivity on ML160 HMFL, ML140 SMT, or ML140 MOD therefore we fail to reject the null hypothesis. However, the p-value for changeovers on ML160 SMT was less than $0.05 \alpha$ meaning changeovers on this line affect productivity, therefore we reject the null hypothesis.

\subsection{Simple Linear Regression}

Although no hypothesis was stated for simple linear regression, this analysis was done to determine which variables were significant with the effect on other variables. According to this analysis, both shift and management do not affect quality. It can be concluded that day, night, and weekend shift tend to produce the same defects for the same reason. Likewise, adding or reducing managers or support staff, does not impact quality defects during production. To determine what causes quality defects, further investigation will need to be conducted.

\subsection{Correlation}

To determine if there was any correlation between productivity and quality, correlation analysis was also conducted using Microsoft Excel. For all value streams, correlation between productivity and quality was less than 0.1 . As this is close to zero, this represents no correlation. Thus, if production has a high productivity shift (units/labor-hour), quality defects will not necessarily be high on that shift. Other variables contribute to producing quality defects.

\section{Discussion}

\subsection{Research Questions of the Study}

There were three research questions posed to guide the study:

First question has to be answered across all three shifts. Both ML160 HMFL and ML140 MOD ANOVA analysis indicate that productivity is statistically different. However, both SMT lines indicate that productivity is not different between the shifts. Knowing this, we can assume that other variables, such as automation or lack of automation are the reasons for these differences.

The answer to the second question is that management support does not hinder performance on day shift, nor does 
the reduced support allow night and weekend shifts to bypass standards. According to the multiple regression analysis, all shifts indicate that management support factor is not significant and does not affect productivity.

Regarding the research question three, from the correlation analysis, this study concludes that none of the value streams indicate any correlation. This implies that if one variable increases or decrease, the other variable will not increase or decrease at a similar rate.

\subsection{Conclusion}

\begin{tabular}{|c|c|c|c|c|}
\hline \multirow{2}{*}{ Value Stream } & \multicolumn{2}{|c|}{ ANOVA } & \multicolumn{2}{c|}{ Multiple Regression } \\
Difference & No Difference & Effect (variable) & No Effect \\
\hline ML160 HMFL & $\begin{array}{c}\mathrm{X} \\
(2 n d \text { sh shf }\end{array}$ & & & $\mathrm{X}$ \\
\hline ML160 SMT & & $\mathrm{X}$ & Changeovers & \\
\hline ML140 SMT & & $\mathrm{X}$ & & $\mathrm{X}$ \\
\hline ML140 MOD & $\begin{array}{c}\mathrm{X} \\
\text { (2nd shffi }\end{array}$ & & & $\mathrm{X}$ \\
\hline
\end{tabular}

Figure 3. Productivity summary chart: shift comparison

Description: The productivity summary chart provides visual representation of statistical analysis for ANOVA and Multiple Regression.

This study had two hypotheses. First hypothesis pertains to all value streams:

$\mathrm{H}_{0}$ : All shifts (day, night, and weekend) have the same productivity

$\mathrm{H}_{1}$ : There is a difference in productivity in at least one shift for each value stream

Based on the ANOVA analysis outcomes, we rejected the null hypothesis for both ML160 HMFL and ML140 MOD, denoting that there was a difference in productivity from day shift and night shift. For both value streams, the average productivity is higher on night shift, meaning that night shift is more productive than day shift as it pertains statistically. Alternatively, we failed to reject the null hypothesis for both SMT value streams, denoting that there is no difference in productivity across all of the shifts. To determine what factors cause ML160 HMFL and ML140 MOD to have different productivity in shift compared to ML160 SMT and ML140 SMT that were the same in productivity, multiple regression was used to determine significance of variables.

The second hypothesis for this study was used to determine which specific factors affect productivity. The hypothesis is as follows:

$\mathrm{H}_{0}$ : Factors such as shift, supervisor support, and number of changeovers, do not affect productivity

$\mathrm{H}_{1}$ : Different factors do affect productivity

Based on results of the multiple regression analysis, ML160 SMT was the only value stream with a significant factor. The factor that affected productivity was the number of changeovers. This holds true, knowing that changing over the line causes downtime. Operator hours do not stop during this time, but product produced does, resulting in lower productivity. Both ML140 value streams build high volume product so changeovers were limited. However, ML160 HMFL build high mix product and had a similar to ML160 SMT number of changeovers. Nonetheless, ML160 HMFL did not indicate that changeovers significantly impacted productivity. It can be assumed that changeovers on the ML160 SMT value stream took longer than changeovers on the ML160 HMFL value stream. The SMT line, being more automated, requires more machine setup to change the line over, while the HMFL is more manual labor where machine setup is very limited. For this reason, it explains why changeovers only affect the ML160 SMT value stream.

Lastly, correlation and simple linear regression were used to help better understand the data between the different value streams and shifts. Using the correlation analysis, we can conclude that productivity and quality are not related. This means that if productivity is increased, quality defects will not increase unless other factors are introduced. The ultimate goal for companies like Daktronics is to increase productivity while also decreasing quality defects. 
Simple linear regression was used to analyze individual factors that may contribute to increasing or decreasing quality output. From this analysis, it is concluded that 'shift' and 'management' factors do not affect quality output for any value stream. However, changeovers only affect ML160 HMFL and not ML160 SMT. This could imply that, due to being a less automated, manual process, the ML160 HMFL is more likely to produce greater quality defects compared to its automated counterpart.

\subsection{Recommendation}

From the results, the two value streams that could be classified as medium to low automation resulted in productivity that was statistically different between all shifts. The other two value streams, classified as full automation, resulted in productivity that was not statistically different between each shift. Based on this, it can be assumed that automation plays a role in standardizing productivity from shift to shift. Those with low automation can be affected by other variables, while high automation makes those variables null and void. From that, further analysis at Daktronics needs to be done in a completely manual manufacturing setting to conclude whether automation plays a role in productivity.

The two shifts were statistically different in productivity, both had higher productivity on night shift than day shift. It is difficult to conclude that night shift is more productive than day shift. Along with more analysis in automation and conducting a study in a completely manual manufacturing setting, further analysis should be conducted on human factors of Daktronics staff. Such variables as skill of a worker, experience or length of employment, and age of a worker can be investigated among other variables. How do these variables affect productivity at Daktronics and can they be tied back to a shift? Do certain levels of skills, experience, or age gravitate to night shift to make it more productive? These questions may need to be studied to fully understand difference in shift work.

For Daktronics, the next step is to study the two value streams that differ in productivity. If it is automation that prevents differences from occurring, then ways to automate production need to be evaluated. Although, capital investment for automated equipment may not be feasible, standardizing processes and reducing potential for difference will also need to be analyzed. Changeovers are another area that needs to be assessed along with the ways to reduce changeovers in order to help productivity on the ML160 SMT value stream.

Although this study only focused on specific samples of production at Daktronics, the results can be induced for other departments within Daktronics or other factories and industries outside of Daktronics that have similar style of production.

\section{Acknowledgements}

Foremost, I would like to express my sincere gratitude to my advisor, Dr. Ekaterina Koromyslova, for your support in this study, your knowledge, the hard work that you put into reviewing, and ultimately your guidance in this study.

Furthermore, I would like to thank Dr. Carrie Steinlicht, for joining this committee and offering insightful comments.

Lastly, I would like to thank Daktronics, my current and past supervisors for allowing me to do this study, the engineers and managers for your assistance with data, and the production staff in EA for allowing me to study you.

\section{References}

Al-Refaie, A., Najdawi, R., \& Sy, E. (2015). Using DEA Window Analysis to Measure the Efficiencies of Blowing Machines in Plastics Industry. Jordan Journal of Mechanical and Industrial Engineering, 10, 27-38.

Bowler, N., \& Gibson, H. (2015). Fatigue and its contribution to railway incidents. Rail Safety and Standards Board. (Special Topic Report).

Costa, G. (2010). Shift Work and Health: Current Problems and Preventative Actions. Department of Occupational Health, University of Milano, 1(2), 112-123. https://doi.org/10.5491/SHAW.2010.1.2.112

Fatigue. (n.d.). Dictionary.com Unabridged. Retrieved September 30, 2017, from http://www.dictionary.com/browse/fatigue

Frehse, J. (2012). The Death of the 8-Hour Shift. Workforce, 44-48. Retrieved from http://www.industryweek.com

Grossman, J. (1978). Fair Labor Standards Act of 1938: Maximum Struggle for a Minimum Wage. Monthly Labor Review, 101(6), 22-30.

Kalmbach, D. A., Pillai, V., Cheng, P., Arnedt, J. T., \& Drake, C. L. (2015). Shift work disorder, depression, and anxiety in the transition to rotating shifts: the role of sleep reactivity. Sleep Medicine, 16, 1532-1538. https://doi.org/10.1016/j.sleep.2015.09.007 
King, S. L., \& Williams, H. B. (1985). Shift work pay differentials and practices in manufacturing. Monthly Labor Review: Bureau of Labor Statistics, 26-33.

Ledebur, L. C., \& Moomaw, R. C. (1983). A Shift-Share Analysis of Regional Labor Productivity in Manufacturing. Growth and Change, 2-9. https://doi.org/10.1111/j.1468-2257.1983.tb00390.x

Lee, M. L., Howard, M. E., Horrey, W. J., Liang, Y., Anderson, C., Shreeve, M. S., \& Czeisler, C. A. (2016). High risk of near-crash driving events following night-shift work. PNAS, 113(1), 176-181. https://doi.org/10.1073/pnas.1510383112

National Conference of State Legislatures. (2017). State Minimum Wages 2017 Minimum Wages by State. Retrieved from http://www.ncsl.org/research/labor-and-employment/state-minimum-wage-chart.aspx

National Sleep Foundation. (2017). What is Circadian Rhythm? Retrieved September 30, 2017, from https://sleepfoundation.org/sleep-topics/what-circadian-rhythm

Ogiński, A., Ogińska, H., \& Pokorski, J. (2000). Internal and External Factors Influencing Time-Related Injury Risk in Continuous Shift Work. International Journal of Occupational Safety and Ergonomics, 6(3), 405-442. https://doi.org/10.1080/10803548.2000.11076464

Pencavel, J. (2014). The Productivity of Working Hours. Department of Economics, Stanford University and the Institute for the Study of Labor, 125(589), 2052-2076.

Productivity. (n.d.). Dictionary.com Unabridged. Retrieved September 11, 2017, from http://www.dictionary.com/browse/productivity

Sanne, R. (2016). Assessing your workload. Industrial Engineer, 48(1), 37-39. Retrieved from www.iienet.org/IEmagazine

Shift Work - Overview. (2017). Sleep Education.org. Retrieved September 30, 2017, from http://www.sleepeducation.org/essentials-in-sleep/shift-work

Travis, R. C., Balkwill, A., Fensom, G. K., Appleby, P. N., Reeves, G. K., Wang, X.-S., \& Beral, V. (2016). Night Shift Work and Breast Cancer Incidence: Three Prospective Studies and Meta-analysis of Published Studies. JNCI Journal of the National Cancer Institute, 108(12), djw169. https://doi.org/10.1093/jnci/djw169

U.S. Department of Health and Human Services, Centers for Disease Control and Prevention, National Institute for Occupational Safety and Health. (2004). Overtime and Extended Work Shifts: Recent Findings on Illnesses, Injuries, and Health Behaviors. DHHS (NIOSH).

U.S. Office of Personnel Management (OPM). (2017). Appropriated fund operating manual (Subchapter S8. Pay Administration S8-4).

Retrieved

from https://www.opm.gov/policy-data-oversight/pay-leave/pay-systems/federal-wage-system/\#url=Appropriated-Fu nd 